\title{
Penyuluhan Peraturan Daerah Kalimantan Timur No 7 Tahun 2019 Tentang Adaptasi dan Mitigasi Perubahan Iklim
}

\author{
Arief Muliawan', Ahmad Yani ${ }^{2 *}$ \\ 1,2 Program Studi Teknik Mesin Sekolah Tinggi Teknologi Industri Bontang, Indonesia \\ 1,2 Jl. Brigjend Katamso No. 40 Bontang Kalimantan Timur \\ ${ }^{*}$ yanibima@gmail.com
}

\begin{abstract}
East Kalimantan Province is very vulnerable to climate change, so it needs policies and strategies in managing climate change impacts through adaptation and mitigation actions. So it is necessary to stipulate local regulations on climate change adaptation and mitigation. Management of climate change in East Kalimantan is one of the local government's efforts in providing guarantees to the community to get a quality living environment. The purpose of this community service activity is to provide understanding to residents regarding East Kalimantan Regional Regulation No. 7 of 2019 concerning climate change adaptation and mitigation. The method of implementing this community service activity is in the form of counseling and discussion of East Kalimantan Regional Regulation No. 7 of 2019 concerning climate change adaptation and mitigation.

Based on the results of community service activities related to the extension of East Kalimantan Regional Regulation No. 7 of 2019 regarding climate change adaptation and mitigation, it was concluded that many people still do not know about the regional regulation. Efforts to mitigate and adapt to climate change are not only the responsibility of the Government, but also the responsibility of the DPR. The DPR's climate change mitigation and adaptation efforts can be carried out through the implementation of its three functions, namely the budget function, the supervisory function, and the legislative function. Every stakeholder, including the community, must mitigate and adapt to climate change, because adaptation and mitigation is the key to addressing climate change, which is the key to reducing greenhouse gas emissions and increasing carbon stocks to reduce the impact of climate change. The active role of the regional government in formulating policies related to climate change is a must, the policy is expected to be a direction for stakeholders in East Kalimantan.
\end{abstract}

Keywords: Adaptation, mitigation, climate change.

\begin{abstract}
Abstrak
Provinsi Kalimantan Timur sangat rentan dengan perubahan iklim, sehingga perlu kebijakan dan strategi dalam pengelolaan dampak perubahan iklim melalui aksi adaptasi dan mitigasi. Maka perlu nenetapkan peraturan daerah tentang adaptasi dan mitigasi perubahan iklim. Pengelolaan perubahan iklim di Kalimantan Timur merupakan salah satu upaya pemerintah daerah dalam memberikan jaminan kepada masyarakat untuk mendapatkan lingkungan hidup yang berkualitas. Tujuan dari kegitan pengabdian masyarakat ini yaitu memberikan pemahaman terhadap warga terkait Peraturan Daerah Kalimantan Timur No 7 Tahun 2019 tentang adaptasi dan mitigasi perubahan iklim. Metode pelaksanaan kegiatan pengabdian masyarakat ini berupa penyuluhan dan diskusi terhadap peraturan Daerah Kalimantan Timur No 7 Tahun 2019 tentang adaptasi dan mitigasi perubahan iklim.

Berdasarkan hasil kegiatan pengabdian masyarakat terkait penyuluhan Peraturan Daerah Kalimantan Timur No 7 Tahun 2019 tentang adaptasi dan mitigasi perubahan iklim disimpulkan bahwa masyarakat masih banyak yang belum mengetahui terkait peraturan daerah tersebut. Upaya mitigasi dan adaptasi perubahan iklim tidak hanya menjadi tanggung jawab Pemerintah, tetapi juga merupakan tanggung jawab DPR. Upaya mitigasi dan adaptasi perubahan iklim DPR dapat dilakukan melalui pelaksanaan ketiga fungsinya, yaitu fungsi anggaran, fungsi pengawasan, dan fungsi legislasi. Setiap pemangku kepentingan, termasuk masyarakat, harus melakukan mitigasi dan adaptasi terhadap perubahan iklim, karena adaptasi dan mitigasi merupakan kunci untuk mengatasi perubahan iklim yaitu kunci untuk mengurangi emisi gas rumah kaca dan meningkatkan cadangan karbon untuk mengurangi dampak perubahan iklim. Peran aktif penerintah daerah dalam merumuskan kebijakan terkait perubahan iklim merupakan suatu keharusan, kebijakan tersebut diharapkan dapat menjadi arahan bagi para pemangku kepentingan di Kalimantan Timur.
\end{abstract}

Kata kunci: Adaptasi, mitigasi, perubahan iklim. 


\section{PENDAHULUAN}

Berdasarkan data historis curah hujan selama 130 tahun yang dikumpulkan oleh BMKG teridentifikasi adanya trend intensitas dan frekwensi hujan ekstrem yang semakin tinggi (Siswanto et al, 2016). Sumber daya alam harus dikelola secara berkelanjutan dan berkeadilan untuk mengendalikan perubahan iklim, dikarenakan Provinsi Kalimantan Timur sangat rentan dengan perubahan iklim (https://dprd.kaltimprov.id), sehingga perlu kebijakan dan strategi dalam pengelolaan dampak perubahan iklim melalui aksi adaptasi dan mitigasi. Maka perlu nenetapkan peraturan daerah tentang adaptasi dan mitigasi perubahan iklim. Perubahan iklim didefinisikan berubahnya iklim yang diakibatkan langsung maupun tidak langsung oleh aktivitas manusia yang menyebabkan perubahan komposisi atmosfer secara global serta perubahan variabilitas iklim alamiah yang teramati pada kurun waktu yang dapat dibandingan atau bisa juga diartikan sebagai perubahan keadaan cuaca rata-rata atau perubahan distribusi peristiwa cuaca rata-rata (Karnawati, 2020). Mitigasi adalah usaha mengendalikan untuk menguransi resiko akibat perubahan iklim melalui kegiatan yang dapat menurunkan emisi dan meningkatkan penyerapan gas rumah kaca dari berbagai sumber emisi. (Qodriyatun, 2016) Sedangkan adaptasi merupakan suatu proses untuk memperkuat dan membangun strategi antisipasi dampak perubahan iklim serta melaksanakanya sehingga mampu mengurangi dampak negatif dan mengambil manfaat positif (UNDP, 2007).

Berdasarkan pasal 28 A Undang-Undang Dasar 1945 menyatakan bahwa setiap orang berhak untuk hidup serta berhak mempertahankan hidup dan kehitupanya. Artinya pemerintah bersama-sama dengan para pihak mempertahankan daya dukung global supaya semua manusia dapat hidup dalam tingkat kehidupan yang layak.

Pengelolaan perubahan iklim di Kalimantan Timur merupakan salah satu upaya pemerintah daerah dalam memberikan jaminan kepada masyarakat untuk mendapatkan lingkungan hidup yang berkualitas. Pasal tersebut memberikan pengertian yang jelas dan konkrit bahwa UUD 1945 pada hakekatnya menjamin kehidupan dan penghidupan yang baik dan sehat yang diperuntukan bagi bagi setiap masyarakat tanpa terkecuali.

Peran aktif penerintah daerah dalam merumuskan kebijakan terkait perubahan iklim merupakan suatu keharusan, kebijakan tersebut diharapkan dapat menjadi arahan bagi para pemangku kepentingan di Kalimantan Timur dalam mewujudkan pembangunan rendah emisi dan meningkatkan resiliensi daerah terhadap dampak perubahan iklim, dikarenakan persolaan dan issue daerah saat ini diantaranya:

a. Semakin meningkatnya kualitas dan kuantitas bencana ekologis di Provinsi Kalimantan Timur, terutama banjir dan tanah longsor yang memiliki intensitas yang tinggi di Kabupaten/Kota.

b. Belum terintegrasinya kelembagaan di pemerintahan yang concern terhadap issue perubahan iklim, sehingga kebijakan dan program berjalan belum sinergis.

c. Masih meningkatnya alih fungsi kawasan hutan untuk peruntukan lain, dan juga alih fungsi kawasan produktif masyarakat untuk pengembangan infrastruktur, pertambangan dan perkebunan skala besar.

d. Pembukaan kawasan untuk calon Ibu Kota Negara (IKN)

Tujuan dari kegitan pengabdian masyarakat ini yaitu memberikan pemahaman terhadap warga terkait Peraturan Daerah Kalimantan Timur No 7 Tahun 2019 tentang adaptasi dan mitigasi perubahan iklim sehingga dapat menjamin terwujudnya transformasi ekonomi Kalimantan Timur menuju ekonomi hijau melalui penyusunan rencana pembangunan daerah dan tata ruang melalui sosialisai ini dan mewujudkan pembangunan rendah emisi dan meningkatkan kemampuan daerah dan sektor untuk beradaptasi terhadap dampak perubahan iklim. 


\section{METODE PELAKSANAAN}

Metode pelaksanaan kegiatan pengabdian masyarakat ini berupa penyuluhan dan diskusi terhadap peraturan Daerah Kalimantan Timur No 7 Tahun 2019 tentang adaptasi dan mitigasi perubahan iklim yang dihadiri 95 orang dengan berbagai macam latar belakang peserta. Sedangkan tempat pelaksaan pengabdian masyarakat ini bertempat di Hotel Surya Kota Bontang dan waktu pelaksanaanya pada tanggal 5 Juni 2021.

\section{HASIL DAN PEMBAHASAN}

\section{Hasil}

Kegitan pengabdian masyarakat ini untuk memberikan pemahaman terhadap warga terkait Peraturan Daerah Kalimantan Timur No 7 Tahun 2019 tentang adaptasi dan mitigasi perubahan iklim sehingga dapat menjamin terwujudnya transformasi ekonomi Kalimantan Timur menuju ekonomi hijau melalui penyusunan rencana pembangunan daerah dan tata ruang melalui sosialisai ini dan mewujudkan pembangunan rendah emisi dan meningkatkan kemampuan daerah dan sektor untuk beradaptasi terhadap dampak perubahan iklim. Adapun bentuk kegitan pengabdian masyarakat ini seperti ditunjukkan pada gambar 1, 2, 3,4 dan 5 .

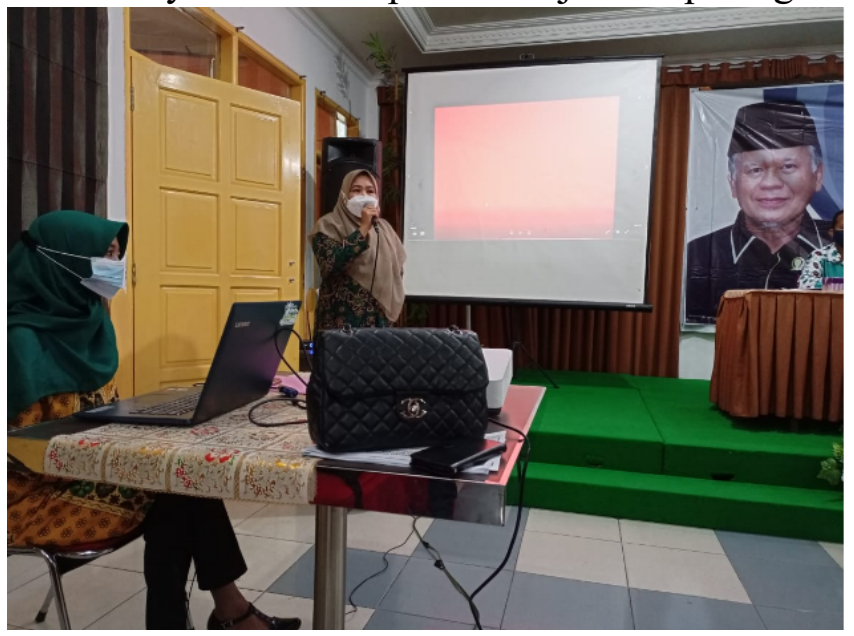

Gambar 1. Dokumentasi pembukaan acara oleh MC

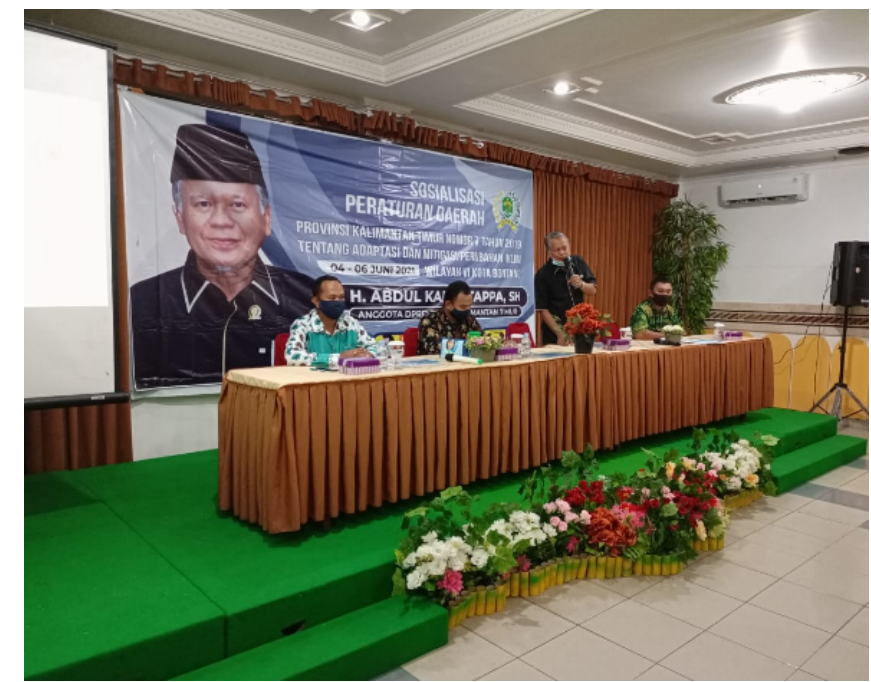

Gambar 2. Dokumentasi sambutan Angota DPRD Provinsi Kaltim 
JPAY Vol. 1 No. 1. 2021

(Jurnal Pengabdian Ahmad Yani) STTI Bontang

URL:

http://www.sttibontang.ac.id/jurnal/index.php/pay

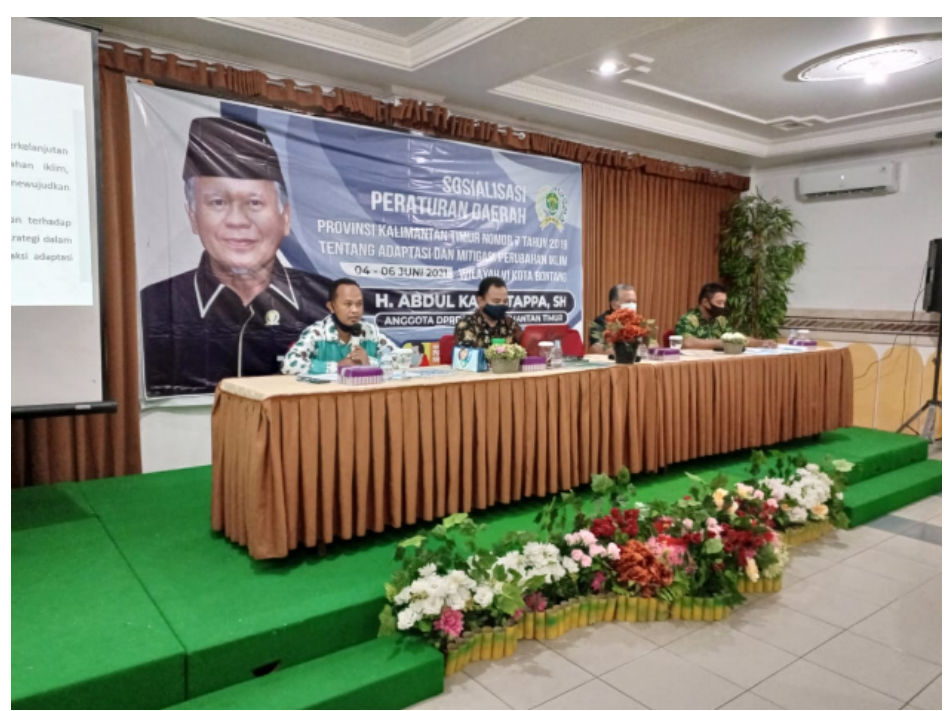

Gambar 3. Dokumentasi penyampaian materi pertama

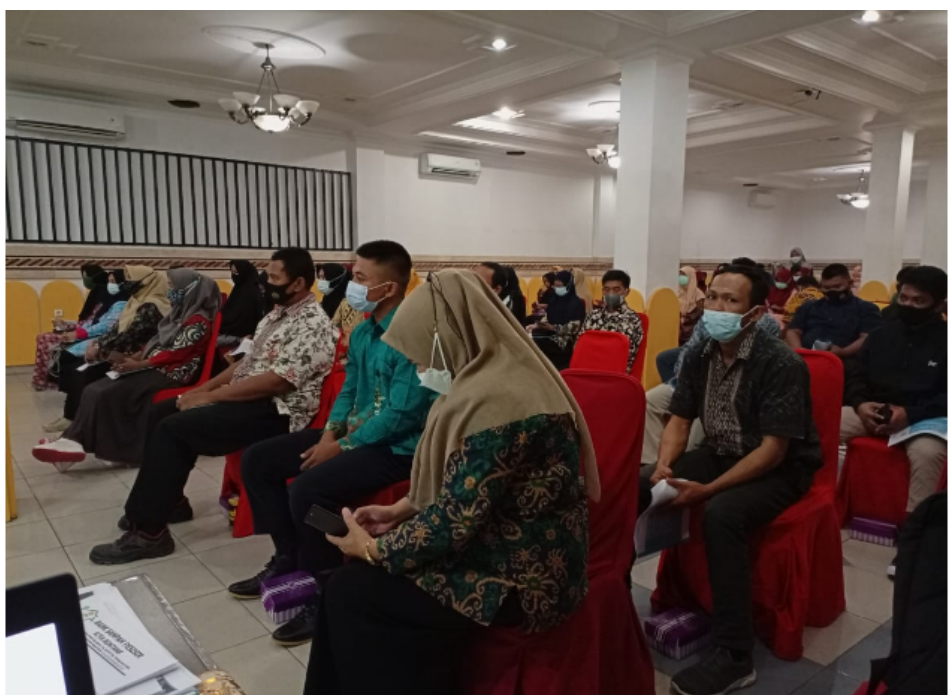

Gambar 4. Dokumentasi peserta penyuluhan

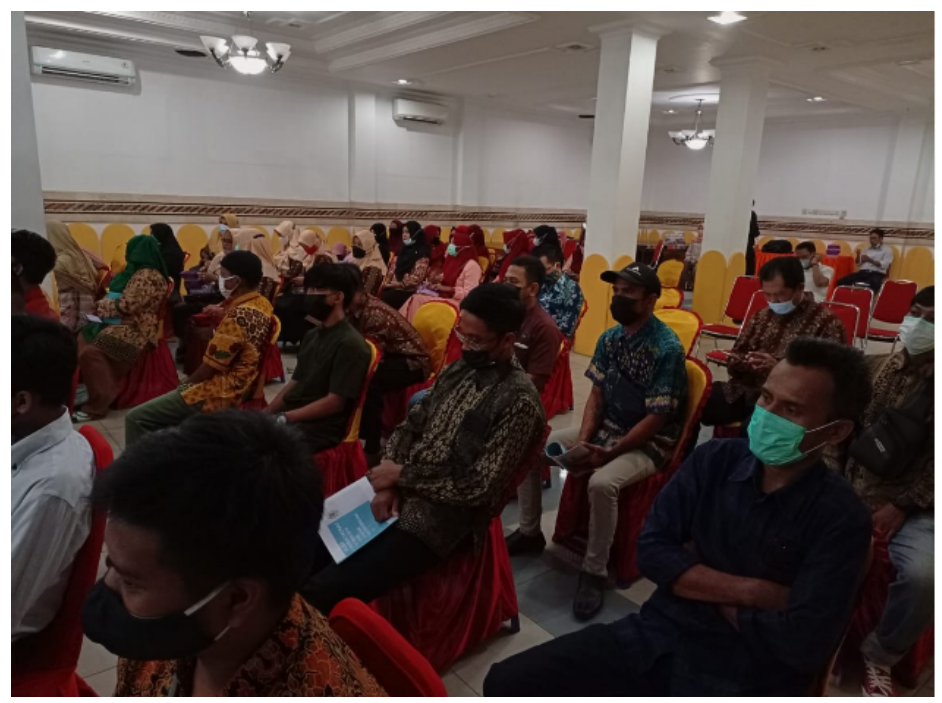

Gambar 5. Dokumentasi peserta penyuluhan 


\section{Pembahasan}

Perubahan iklim dapat terjadi secara lokal, terbatas hingga regional tertentu, atau dapat terjadi di seluruh wilayah permukaan bumi. Perubahan itu ditandai setidaknya oleh empat hal, pertama karena adanya perubahan/kenaikan temperatur secara global, kedua kenaikan tinggi muka air laut, ketiga semakin sering terjadinya kondisi cuaca ekstrim dan lainnya, dan keempat terjadi perubahan pola curah hujan. Untuk mengatasi perubahan iklim membutuhkan langkah antisipasi lebih dini agar Kalimantan Timur mampu beradaptasi dan melakukan mitigasi secara tepat. Masyarakat Kalimantan Timur dapat ikut berperan dalam mitigasi dengan melakukan hal-hal kecil seperti mengurangi penggunaan sampah plastik, dan menanam pohon di lingkungan sekitar. Alternatif terbaik untuk beradaptasi terhadap perubahan iklim adalah dengan beralih ke bentuk-bentuk pembangunan yang lebih berkelanjutan yang menganut empat prinsip uatama pembangunan berkelanjutan, yaitu prinsip keadilan antar generasi, prinsip keadilan dalam satu generasi, prinsip pencegahan dini, dan internalisasi biaya lingkungan serta mekanisme insentif. Peran aktif penerintah daerah dalam merumuskan kebijakan terkait perubahan iklim merupakan suatu keharusan, kebijakan tersebut diharapkan dapat menjadi arahan bagi para pemangku kepentingan di Kalimantan Timur dalam mewujudkan pembangunan rendah emisi dan meningkatkan resiliensi daerah terhadap dampak perubahan iklim,

Asas penyelenggaraan adaptasi dan mitigasi perubahan iklim meliputi:

a. Tanggung jawab;

b. Kelestarian dan berkelanjutan;

c. Keserasian dan keseimbangan;

d. Keterpaduan;

e. Manfaat;

f. Kehati-hatian;

g. Keadilatn;

h. Partisipatif; dan

i. Kearifan lokal.

\section{Adaptasi Perubahan Iklim}

Adapun adaptasi poerubahan iklim meliputi kegiatan :

1. Ketahanan Ekonomi yang dilaksanakan untuk mendukung ketahanan pangan melalui pengembangan sistem data dan informasi pangan, penguatan manajemen usaha tani dan kelembagaan tani, serta perbaikan pengelolaan sarana dan prasarana pendukung usaha pertanian; dan mewujudkan kemandirian energi melalui perbaikan dan konservasi wilayah tangkapan hujan pada daerah aliran sungai yang menjadi sumber pembangkit energi tenaga air, serta optimalisasi pemanfaatan limbah organik dan biomossn serta pengembangan sumber energi dari bahan bakar nabati.

2. Ketahanan sistem kehidupan dilaksanakan untuk penguatan sektor kesehatan, pemukiman dan infrastrukur

3. Ketahanan Ekosistem dan Wilayah Khusus meliputi pengelolaan ekosistem dan daerah aliran sungai melalui pengelolaan berkelanjutan kawasan lahan basah; penguatan kawasan Perkotaan melalui percepatan pencapaian kota tangguh dan sekolah tangguh bencana dan pengintegrasian upaya adaptasi perubahan iklim ke dalam rencana penataan ruang perkotaan; dan pengelolaan pesisir dan pulau kecil melalui pengimplementasian sistem pengelolaan pesisir terpadu, membangun kesiapan masyarakat dalam menghadapi 
perubahan tinggi muka air laut, dan pengembangan sarana penangkapan yang tahan terhadap perubahan cuaca serta pengelolaan bencana pesisir serta pulau kecil.

\section{Mitigasi Perubahan Iklim}

Adapaun mitigasi perubahan iklim di Daerah meliputi kegiatan:

1. Tata guna lahan, alih guna lahan dan hutan meliputi kegiatan:
a. Menurunkan laju alih guna hutan alam di dalam maupun di luar kawasan hutan, termasuk di dalam kawasan lindung dan kawasan budidaya;
b. Melakukan dan mempromosikan rehabilitasi lahan kritis dengan tanarnan pangan dan tanaman-tanaman yang bernilai ekonomi serta menghasilkan jasa lingkungan yang penting untuk mendukung sistem kehidupan lokal, daerah, dan global;
c. Mencegah kebakaran hutan, kebun dan lahan;
d. Menerapkan teknologi pembalakan berdampak minimal pada kegiatan usaha pemanfaatan hasil hutan kayu hutan alam; dan
e. Memfasilitasi perhutanan sosial dan skema pengelolaan hutan berbasis masyarakat.

2. Pengukuran tingkat keberhasilan kegiatan mitigasi di atas, meliputi:
a. Menurunnya nilai kerugian dan jumlah korban bencana terkait;
b. Indeks tutupan hutan minimal pada tingkat 0,51 (nol koma lima puluh satu) pada tahun 2020 dan 0,48 (nol koma empat puluh delapan) pada tahun 2030;
c. Indeks tutupan hutan primer minimal pada tingkat 0,17 (nol koma tujuh belasJ pada tahun 2020 dan 0,16 (no1 koma enam belas) pada tahun 2030;
d. Menurunnya jumlah luas alih guna lahan dengan tutupan hutan bakau; dan
e. Menurunnya angka kejadian kebakaran lahan gambut dan lahan berhutan.

3. Pertanian, meliputi kegiatan:
a. Menerapkan praktek dan paket teknologi pertanian ramah iklim;
b. Melakukan pengembangan wilayah sumber pertumbuhan baru produksi pangan pada daerah dengan risiko ikltm rendah dan dampak lingkungan minimum;

4. Pengukuran tingkat keberhasilan kegiatan mitigasi di atas meliputi:
a. Bertambahnya jumlah luas lahan pertanian tanaman pangan yang dikelola dengan teknologi pertanian ramah iklim;
b. Menurunnya jumlah kejadian gagal panen pertanian akibat kejadian iklim ekstrim dan perubahan ikim.

5. Energi, meliputi kegiatan:
a. Menerapkan penggunaan sumber energi terbarukan dari sumber lokal untuk pembangkitan tenaga listrik terutama untuk listrik perdesaan dan/atau daerah terpencil; dan
b. Menerapkan penghematan penggunaan energi dan penggunaan energi dari sumber energi terbarukan pada kegiatan industri, transportasi, rumah tangga, dan pemerintahan.

6. Pengukuran tingkat keberhasilan kegiatan mitigasi di atas, meliputi :
a. Tercapainya proporsi energi terbarukan dalam bauran energi ketenagalistrikan daerah sebesar $2 \%$ (dua persen) pada tahun 2020 dan 20\% (dua puluh persen) pada tahun 2030; dan
b. Intensitas energi daerah yang terns menurun.

7. Limbah, meliputi kegiatan :
a. Menerapkan pengurangan produksi sampah domestik dan industri lewat pengurangan, penggunaan kembali, dan daur ulang;


b. Mengoptimalkan pemanfaatan limbah domestik dan limbah industri, untuk menghasilkan energi, dan untuk produk lainnya; dan

c. Mendorong efisiensi dan pemanfaatan limbah disektor usaha kehutanan.

8. Pengukuran tingkat keberhasilan kegiatan mitigasi di atas, meliputi :

a. Menurunnya volume produksi sampah domestik per kapita;

b. Meningkatnya jumlah pabrik kelapa sawit yang melakukan penangkapan gas methane; dan

c. Meningkatnya jumlah pemanfaatan limbah di industri dan usaha kehutanan.

\section{KESIMPULAN}

Berdasarkan hasil kegiatan pengabdian masyarakat terkait penyuluhan Peraturan Daerah Kalimantan Timur No 7 Tahun 2019 tentang adaptasi dan mitigasi perubahan iklim disimpulkan bahwa masyarakat masih banyak yang belum mengetahui terkait peraturan daerah tersebut. Upaya mitigasi dan adaptasi perubahan iklim tidak hanya menjadi tanggung jawab Pemerintah, tetapi juga merupakan tanggung jawab DPR. Upaya mitigasi dan adaptasi perubahan iklim DPR dapat dilakukan melalui pelaksanaan ketiga fungsinya, yaitu fungsi anggaran, fungsi pengawasan, dan fungsi legislasi. Setiap pemangku kepentingan, termasuk masyarakat, harus melakukan mitigasi dan adaptasi terhadap perubahan iklim, karena adaptasi dan mitigasi merupakan kunci untuk mengatasi perubahan iklim yaitu kunci untuk mengurangi emisi gas rumah kaca dan meningkatkan cadangan karbon untuk mengurangi dampak perubahan iklim. Peran aktif penerintah daerah dalam merumuskan kebijakan terkait perubahan iklim merupakan suatu keharusan, kebijakan tersebut diharapkan dapat menjadi arahan bagi para pemangku kepentingan di Kalimantan Timur

\section{Ucapan terimakasih}

Penulis mengucapkan terima kasih kepada Ketua DPRD Provinsi Kalimantan Timur yaitu Drs. H. Makmur HAPK dan Anggota DPRD Provinsi Kalimantan Timur . H. Abdul Kadir Tapa, S.H yang telah memberikan kepercayaan kepada penulis sebagai pemateri dalam melakukan penyuluhan Peraturan Daerah Kalimantan Timur No 7 Tahun 2019 tentang adaptasi dan mitigasi perubahan iklim, dan telah menfasilitasi penuh kegitan pengabdian masyarakat ini dengan dukungan tempat pelaksanaan serta dana pelaksanaan pengabdian masyarakat.

\section{DAFTAR PUSTAKA}

Karnawati,. D. (2020), Pentingnya Mitigasi dan Adaptasi terhadap Perubahan Iklim, Pusat kajian Sumberdaya Bumi Non Konvesional. Universitas Gajag Mada, Yogyakarta

Peraturan Daerah Kalimantan Timur No 7 Tahun 2019 Tentang Adaptasi dan Mitigasi Perubahan Iklim. DPRD Prov. Kaltim. 2019

Qodriyatun,. S.N. Upaya Adaptasi dan Mitigasi Perubahan Iklim. Jurnal Info Singkat. Vol. 8. No. 1. 2016. Hal. 9-12

Siswanto, G. J. van Oldenborgh, G. van der Schrier, R. Jilderda, B. van den Hurk, Temperature, extreme precipitation, and diurnal rainfall changes in the urbanized Jakarta city during the past 130 years, International Journal of Climatology 36 (2016) hal. 3207-3225. 
UNDP. 2007. Sisi Lain Perubahan Iklim, Mengapa Indonesia harus Beradaptasi untuk Melindungi Rakyat Miskinnya. Jakarta: UNDP Indonesia Country.

Undang-Undang Dasar 1945

\section{Profil Penulis:}

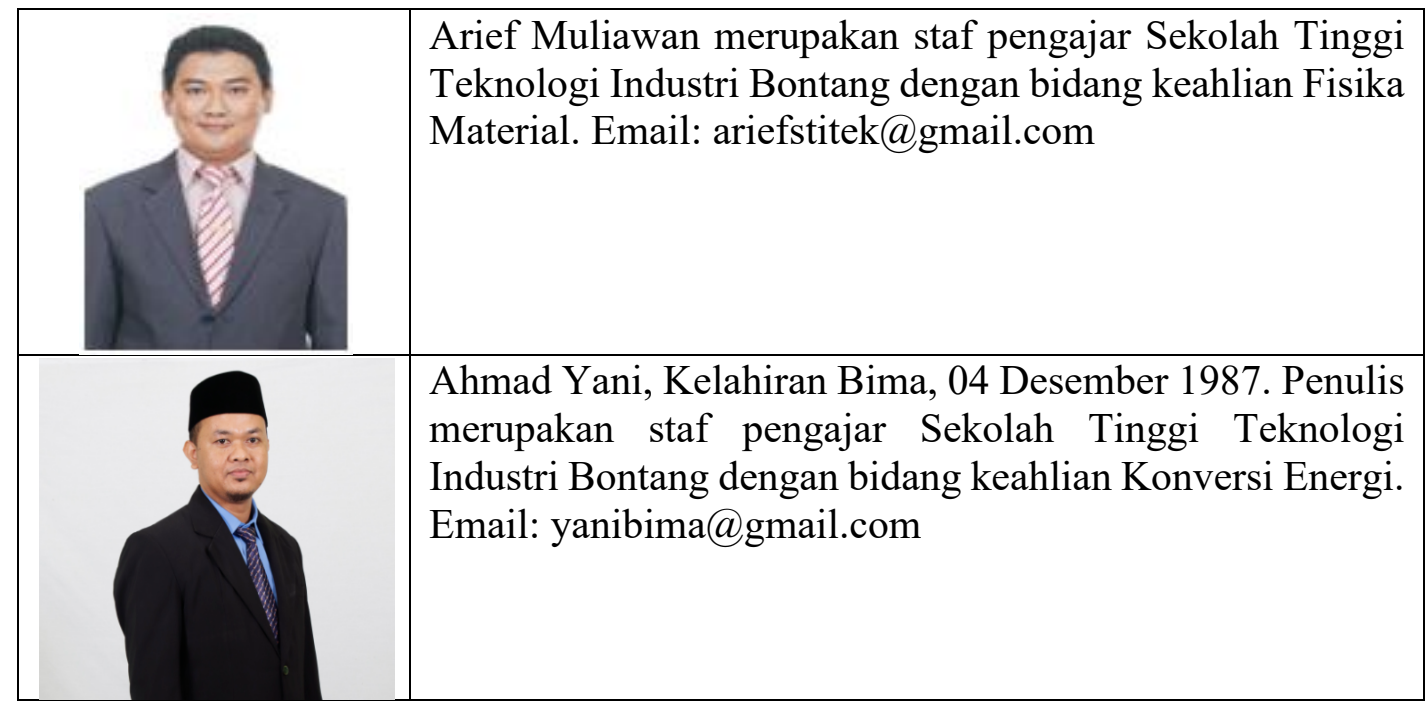

